\title{
Potential Contribution of the Intestinal Microbiome to Phenethylamine-Induced Hyperthermia
}

\author{
Amal Aburahma ${ }^{a}$ Sudhan Pachhain ${ }^{b}$ Sayantan Roy Choudhury ${ }^{b}$ \\ Srishti Rana ${ }^{b}$ Vipa Phuntumart ${ }^{b}$ Ray Larsen ${ }^{b}$ Jon E. Sprague ${ }^{a}$ \\ aThe Ohio Attorney General's Center for the Future of Forensic Science, Bowling Green State University, \\ Bowling Green, $\mathrm{OH}, \mathrm{USA} ;{ }^{\mathrm{b}}$ The Department of Biological Sciences, Bowling Green State University, \\ Bowling Green, $\mathrm{OH}$, USA
}

\section{Keywords}

Hyperthermia · Sympathomimetic · Uncoupling proteins ·

Gut microbiome

\begin{abstract}
Phenethylamines (e.g., methamphetamine) are a common source of drug toxicity. Phenethylamine-induced hyperthermia (PIH) can activate a cascade of events that may result in rhabdomyolysis, coagulopathy, and even death. Here, we review recent evidence that suggests a potential link between the gut-brain axis and $\mathrm{PIH}$. Within the preoptic area of the hypothalamus, phenethylamines lead to changes in catecholamine levels, that activate the sympathetic nervous system (SNS) and increase the peripheral levels of norepinephrine (NE), resulting in: (1) the loss of heat dissipation through $a_{1}$ adrenergic receptor $\left(a_{1}\right.$-AR)-mediated vasoconstriction, (2) heat generation through $\beta$-AR activation and subsequent free fatty acid (FFA) activation of uncoupling proteins (UCPs) in brown and white adipose tissue, and (3) alteration of the gut microbiome and its link to the gut-brain axis. Recent studies have shown that phenethylamine derivatives can influence the composition of the gut microbiome and thus its metabolic potential. Phenethylamines increase the relative
\end{abstract}

karger@karger.com

(c) 2021 S. Karger AG, Basel

www.karger.com/bbe

Karger' level of Proteus which has been linked to enhanced NE turnover. Bidirectional fecal microbial transplants (FMT) between $\mathrm{PIH}$-tolerant and PIH-naïve rats demonstrated that the transplantation of gut microbiome can confer phenotypic hyperthermic and tolerant responses to phenethylamines. These phenethylamine-mediated changes in the gut microbiome were also associated with epigenetic changes in the mediators of thermogenesis. Given the significant role that the microbiome has been shown to play in the maintenance of body temperature, we outline current studies demonstrating the effects of phenethylamines on the gut microbiome and how these microbiome changes may mechanistically contribute to alterations in body temperature.

(c) 2021 S. Karger AG, Basel

\section{Introduction}

According to the National Forensic Laboratory Information System (NFLIS) snapshot report [2019], psychostimulants, namely the phenethylamines, remain the most commonly seen drugs in forensic science laboratories. A majority of these cases involved methamphetamine, i.e., 127,533 of the 134,480 phenethylamine cases 


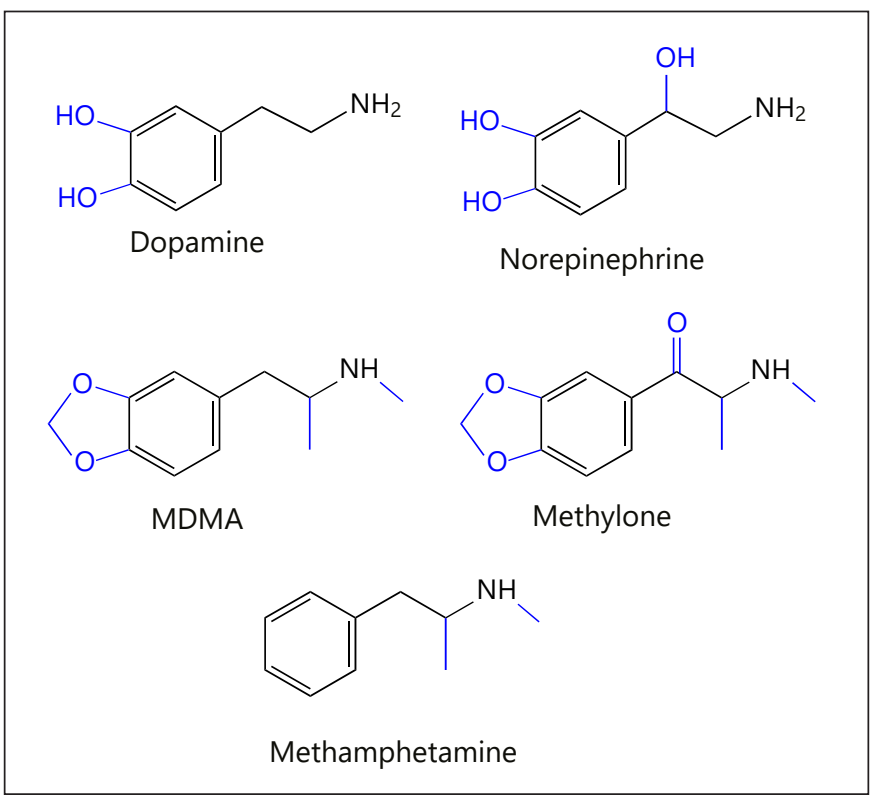

Fig. 1. Chemical structure of common phenethylamines. The phenethylamine portion of the molecule is indicated in black. Functional group differences are indicated in blue.

[NFLIS, 2019]. The routine use of phenethylamines dates back to the Han Dynasty (206 BC to 220 AD) and the use of the ma huang plant [Lee, 2011] which was subsequently found to contain ephedra [Lee, 2011]. Endogenously, catecholamine neurotransmitters, such as dopamine (DA) and norepinephrine (NE), also contain the phenethylamine pharmacophore (Fig. 1). Exogenously administered phenethylamine-type psychostimulants are therefore commonly referred to as "sympathomimetic" agents because they have pharmacological and toxicological properties that "mimic" NE, the predominant neurotransmitter of the sympathetic nervous system (SNS). Commonly used phenethylamine-type psychostimulants include methamphetamine, 3,4-methylenedioxymethamphetamine (MDMA), and the synthetic cathinones ("bath salts") such as methylone, the $\beta$-keto analog of MDMA (Fig. 1).

In general, phenethylamines enhance the release of and block the reuptake of catecholamines to activate the SNS and central nervous system (CNS) [reviewed in Banks et al., 2014]. Pharmacologically, the increased levels of DA within the nucleus accumbens (NAc) have been associated with the rewarding effects of these agents [Banks et al., 2014]. Toxicologically, phenethylamines can induce a sympathomimetic syndrome characterized by diaphoresis, tachycardia, muscle rigidity, rhabdomy-

The Microbiome and Drug-Induced Hyperthermia olysis, metabolic acidosis, seizures, hyperkalemia, coagulopathy, and marked hyperthermia [Rusyniak and Sprague, 2005]. The hyperthermia induced by phenethylamines has further been linked to acute kidney injury, rhabdomyolysis, and ultimately death [Screaton et al., 1992; Borek and Holstege, 2012; O'Connor et al., 2015; Sprague et al., 2018]. It has been suggested that hyperthermia associated with phenethylamines is the initiating factor for rhabdomyolysis and coagulopathy, namely disseminated intravascular coagulation (DIC) [Screaton et al., 1992]. Phenethylamine-induced hyperthermia (PIH) triggers a cascade of events that releases tissue thromboplastin, initiating coagulation and DIC [Kendrick et al., 1977]. These agents are often used at all-night dance parties, with the combination of exertion and hyperthermia postulated to contribute to the onset of rhabdomyolysis [Campbell and Rosner, 2008]. Death and acute renal failure can occur as a result of DIC and rhabdomyolysis [Armenian et al., 2013]. Because these events are secondary to hyperthermia, the cellular mechanisms that mediate phenethylamine-generated thermogenesis are essential to the understanding and management of patients suffering from $\mathrm{PIH}$.

Given that recent studies indicated a link between the microbiome-gut-brain axis and the regulation of body temperature [Rosenbaum et al., 2015; Li et al., 2019], and that phenethylamines can alter the composition of the gut microbiome [Ridge et al., 2019; Angoa-Pérez et al., 2020], we examine here the potential cellular mechanisms that may link the microbiome-gut-brain axis to PIH.

\section{General Overview of PIH}

The involvement of central and peripheral mediators in the production of PIH has been investigated by our laboratory and others. Centrally, it is proposed that PIH occurs via the modulation of the hypothalamus as a result of the release of serotonin (5-HT) [Eyer and Zilker, 2007]. Phenethylamine treatment leads to the alteration of the microcircuitry within the preoptic area (POA) of the hypothalamus, which, in turn, results in acetylcholine (ACh) preganglionic ganglia regulation via the activation of 5- $\mathrm{HT}_{2 \mathrm{~A}}$ receptors [Herin et al., 2005, Sprague et al., 2018]. ACh release, in turn, leads to the regulation of the SNS, with subsequent postganglionic NE release modulating the peripheral triggers of hyperthermia [Li and Eisenach, 2002].

Furthermore, $\mathrm{D}_{1} \mathrm{DA}$ receptor activation has also been correlated with centrally mediated hyperthermia. The se- 
lective $\mathrm{D}_{1}$ receptor agonists SKF 81297, SKF 38393, and SKF $75670(10 \mathrm{mg} / \mathrm{kg}$ injected subcutaneously [s.c.]) induced hyperthermia in male mice while the peripherally acting $\mathrm{D}_{1}$ agonist fenoldopam $(10 \mathrm{mg} / \mathrm{kg}$ s.c.) had no effect on body temperature [Sánchez, 1989]. These results are consistent with the study by Mechan et al. [2002] regarding the influence of the $\mathrm{D}_{1}$ antagonist $\mathrm{SCH} 23390$ on MDMA-induced hyperthermia. In their study, SCH $23390(0.3-2.0 \mathrm{mg} / \mathrm{kg})$ was shown to antagonize MDMAinduced hyperthermia in a dose-dependent manner in rats.

In addition, phenethylamine-induced brain hyperthermia has been studied extensively. Brown and Kiyatkin [2004] examined the influence of MDMA ( $9 \mathrm{mg} / \mathrm{kg}$ s.c.) on temperatures in certain brain regions (the NAc and hippocampus) and skeletal muscle (SKM) in male rats. At an ambient temperature of $23^{\circ} \mathrm{C}$ under resting conditions, a moderate but extended hyperthermic response was observed, with both the NAc and hippocampus displaying faster and higher temperature elevations than the SKM. They suggested these changes occurred as the result of metabolic neural activation. They also examined the effects of MDMA in rat models of human drug use and restricted heat dissipation from the brain. The rats under conditions modeling human drug use (i.e., social interaction with females at a warm temperature) showed significant potentiation of MDMA-induced brain hyperthermia. The rats under restricted heat dissipation from the brain (i.e., chronic occlusion of the jugular vein) illustrated potentiation of MDMA-induced brain hyperthermia due to the enhanced intrabrain heat accumulation secondary to reduced cerebral blood outflow. These findings suggest that the use of MDMA under "party" conditions can result in very dangerous and possibly fatal brain hyperthermia compared to standard laboratory conditions. Kiyatkin et al. [2014] expanded their original findings and assessed MDMA-mediated brain hyperthermia in the NAc, temporal muscle, and facial skin in freely moving rats with chronic implantation of thermocouple microsensors in these areas. Data analysis showed a mild MDMA-induced brain hyperthermic response under quiet resting conditions, and critically significant enhancements of MDMA-resulting brain hyperthermia during social interaction at a warm temperature. Here, the continuous facial skin and temporal muscle monitoring revealed peripheral vasoconstriction as an important mechanism contributing to the potentiation of MDMA-induced brain hyperthermia under conditions mimicking drug consumption by humans.
The potential of the synthetic cathinone analogues methylone and 3,4-methylenedioxypyrovalerone (MDPV) to cause brain hyperthermia was also examined by Kiyatkin et al. [2015]. In this study, the treatment of methylone (1-9 $\mathrm{mg} / \mathrm{kg}$ s.c.) or MDPV (0.1-1 mg/kg s.c.) resulted in a dosedependent elevation in brain temperature and peripheral vasoconstriction under quiet resting conditions. However, the social interaction and warm temperature did not potentiate methylone- or MDPV-induced brain hyperthermia, as noted with MDMA treatment under similar conditions. The authors concluded that, although both methylone and MDPV are structurally similar to MDMA, the critical enhancement in brain hyperthermia that potentially results from peripheral vasoconstriction did not occur in a human drug use model in rodents.

It has been suggested that, peripherally, hyperthermia results from the combined loss of heat dissipation modulated by peripheral vasoconstriction and heat production triggered by uncoupling proteins (UCPs) [Mills et al., 2003] (Fig. 2). These mechanisms resemble those proposed for generating heat upon exposure to cold [Tansey and Johnson, 2015]. The reduction in heat dissipation following MDMA administration was shown by Pedersen and Blessing [2001] to occur via cutaneous vasoconstriction in rabbits. Subsequently, the administration of the $\alpha_{1}$ adrenergic receptor $\left(\alpha_{1}-\mathrm{AR}\right)$ antagonist prazosin $(0.2 \mathrm{mg} /$ $\mathrm{kg}$ intraperitoneally [i.p.]) $30 \mathrm{~min}$ prior to MDMA was shown to attenuate PIH [Sprague et al., 2003]. These results suggested that the activation of $\alpha_{1}$-AR after SNS activation contributes to thermoregulation via peripheral vasoconstriction. This activation occurs as a result of $\mathrm{NE}$ release following the administration of phenethylamine derivatives. In the brown adipose tissue (BAT), NE binds to the plasma membrane $\beta_{1}-\mathrm{AR}, \beta_{2}-\mathrm{AR}$, and $\beta_{3}$-AR, leading to the activation of lipases that trigger the liberation of free fatty acids (FFA) from triglycerides [Sprague et al., 2007]. FFAs are then transported to the mitochondrion by fatty acid translocase FAT/CD36 in conjunction with carnitine palmitoyltransferase I (CPT I), where they bind to UCP1 and UCP3 [Campbell et al., 2004; Sprague et al., 2007]. This binding activates heat production by dissipating the proton gradient across the mitochondrial inner membrane, creating a futile cycle that results in the production of heat [Cannon and Nedergaard, 2004] (Fig. 2).

Riley et al. [2016] demonstrated that UCP1 and UCP3 play complementary roles; UCP1 triggers thermogenesis and UCP3 maintains it. In their study, mice lacking UCP3 displayed a normal response to NE, but had impaired methamphetamine-induced hyperthermia and diminished lipopolysaccharide (LPS) thermogenesis; the UCP1 knockout 


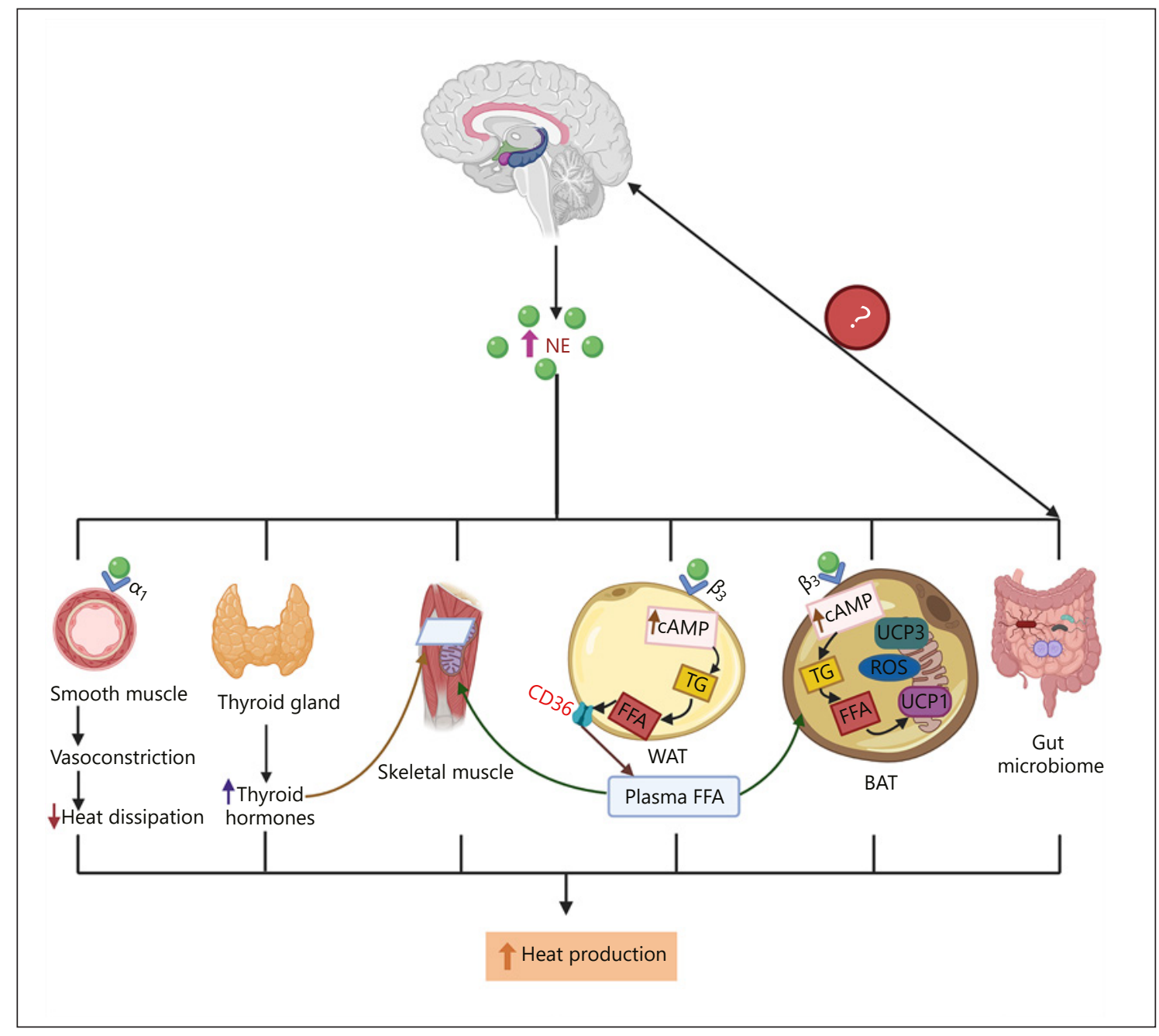

Fig. 2. Schematic diagram of the thermogenic mechanisms involved in phenethylamine-induced hyperthermia (PIH). In this diagram, norepinephrine (NE) release upon phenethylamine administration activates $\beta_{3}$ adrenergic receptors $\left(\beta_{3}-\mathrm{AR}\right)$ on brown adipocytes (brown adipose tissue, BAT) which enhances the release of free fatty acids (FFA). Increased levels of FFA lead to elevating intracellular cyclic adenosine monophosphate (cAMP) levels, which, in turn, induces lipolysis as a result of the induction of adipose triglyceride lipase (ATGL) and hormone-sensitive lipase (HSL). This induction enables BAT to induce the catalysis of intracellular triglycerides (TG) into FFA and glycerol in BAT. These intracellular FFA are consumed as an energy source for uncoupling proteins (UCP) 1 and 3 in BAT and for UCP3 in skeletal muscle (SKM) after being transported via FAT/CD36 transporters. Furthermore, mitochondrial reactive oxygen species (ROS) generated upon phenethylamine challenge and the subsequent NE re-

mice showed a blunted NE and methamphetamine-induced thermogenesis response and an increased response to LPS. Additionally, mice lacking both UCP1 and UCP3 did not show methamphetamine-induced hyperthermia. lease are closely related to UCP1 activation in BAT and possibly contribute to the early peak in hyperthermia. NE release also activates $\alpha_{1}$ adrenergic receptors $\left(\alpha_{1}-A R\right)$ in blood vessels, leading to vasoconstriction and impaired heat dissipation. Thyroid hormone release after hypothalamic activation also contributes to PIH by regulating FFA release and controlling UCP3, FAT/CD36, and sarcoplasmic/endoplasmic reticulum Ca2+ATPase (SERCA1) transcriptional levels. The communication between the gut microbiome and the brain is suggested to be bidirectional, but the effects of the gut microbiome on BDNF levels during PIH is poorly understood. In the gastrointestinal tract (GIT), NE release modulates gut microbiome diversity and colonization, while the gut microbiome alters the critical mediators of PIH including UCP1, UCP3, and TGR5 expression levels in both BAT and SKM. Figure generated using BioRender.

The hypothalamic-pituitary-thyroid axis (HPT axis) has been shown to play a major role in regulating UCP3 expression [Lanni et al., 1999; Watanabe et al., 2006] and PIH [Sprague et al., 2007]. Sprague et al. [2007] showed 
that hypothyroid rats had decreased levels of UCP3 and displayed a hypothermic response to MDMA (40 mg/kg s.c.) treatment. However, chronic administration of levothyroxine $(100 \mu \mathrm{g} / \mathrm{kg}$ i.p.) for 7 days prior to MDMA treatment increased UCP3 protein expression levels and the hyperthermic response to the drug returned. These results suggest that thyroid hormones play an important role in susceptibility to $\mathrm{PIH}$.

Bile acids have also been shown to play a complementary role with thyroid hormone in body temperature regulation. The binding of bile acids to the G protein-coupled receptor (GPCR) TGR5 increases energy expenditure in the BAT and SKM [Watanabe et al., 2006], which, in turn, induces the cAMP-dependent thyroid hormoneactivating enzyme, iodothyronine deiodinase type 2 (D2). D2 converts T4 to 3,5,3-triiodothyronine (T3) which stimulates glucose metabolism and lipolysis [Thomas et al., 2009]. The inhibition of D2 activity using iopanoic acid (IOP; D2 inhibitor, $50 \mathrm{mg} / \mathrm{kg} /$ day i.p. for 7 days) blunted the hyperthermic response to MDMA [Ridge et al., 2019]. The same study also demonstrated that the inhibition of TGR 5 using triamterene (a TGR5 antagonist, $50 \mathrm{mg} / \mathrm{kg}$ i.p.) attenuated MDMA-induced hyperthermia. These results suggest that TGR5 activation plays a contributory role in PIH.

Sex-based differences to PIH have also been an area of interest in our laboratory and others. Wyeth et al. [2009] reported that male and female rats displayed different hyperthermic responses to MDMA $(20 \mathrm{mg} / \mathrm{kg}$ s.c.) treatment; males had significantly elevated hyperthermia, higher levels of plasma NE, and elevated UCP3 expression in the SKM compared to female rats. The hyperthermic response to MDMA $(0.3,1,3$, or $9 \mathrm{mg} / \mathrm{kg}$ i.p.) in male and female rats after they were treated 3 times at 3-h intervals was significantly different [Wallinga et al., 2011]; MDMA-mediated a dose-dependent augmentation in body temperature in the males but not in the females. We examined differences in tolerance to methylone-induced hyperthermia in male and female rats. When male and female rats were treated with methylone $(10 \mathrm{mg} / \mathrm{kg}$ s.c.) once a week, females developed tolerance to methylone-induced hyperthermia by the second week of treatment, and they displayed a hypothermic response to methylone by the third week [Goldsmith et al., 2019]; conversely, tolerance to methyloneinduced hyperthermia was not observed in the male rats until the fifth week of treatment. Additionally, the distinctive differences in tolerance to methylone hyperthermia in the males and females was associated with UCP1, UCP3, and TGR5 gene expression level differenc- es in the BAT and SKM. UCP1 expression levels were reduced in female rats in the SKM and BAT, but UCP3 expression levels increased in both males and females. Only the females displayed elevated levels of TGR5 in the BAT [Goldsmith et al., 2019].

Another mediator of thermogenesis that has been explored is the reactive oxygen species (ROS) [Sanchez-Alavez et al., 2013; Chouchani et al., 2016]. Under normal physiological conditions, some mitochondrial ROS, like $\mathrm{H}_{2} \mathrm{O}_{2}$, act as signaling molecules, both extracellularly and within cells [Sundaresan et al., 1995; Bae et al., 1997; Dickinson et al., 2010]. $\mathrm{H}_{2} \mathrm{O}_{2}$ can pass rapidly through mitochondrial membranes and act as a redox signal from the mitochondrion to the rest of the cell, and vice-versa, by altering a thiol group on a cysteine residue that is involved in redox signaling [Boivin et al., 2010]. Surprisingly, the acute activation of BAT thermogenesis via exposure to cold in mice led to a significant increase in mitochondrial ROS levels, while the depletion of ROS using mitochondrion-targeted antioxidant (MitoQ, $5 \mathrm{mg} / \mathrm{kg}$ i.p.) prior to cold exposure led to a hypothermic response [Chouchani et al., 2016]. Furthermore, NE treatment of BAT resulted in an acute dose-dependent elevation in superoxide levels. Chouchani et al. [2016] suggested that the hypothermic effects after ROS depletion are closely related to UCP1 levels. Wild-type (WT) mice and mice genetically lacking UCP1 were treated with MitoQ prior to cold acclimation. Conversely, UCP1 knockout mice were immune to the hypothermic effect of MitoQ. Their findings suggest that mitochondrial ROS regulate UCP1-dependent thermogenesis. Sanchez-Alavez et al. [2013] investigated the role of ROS in PIH upon methamphetamine treatment. In their study, methamphetamine (60 $\mu \mathrm{M}$ ) induced $\mathrm{H}_{2} \mathrm{O}_{2}$ production in BAT culture. This effect was completely abolished using $\mathrm{N}$-acetyl cysteine (a ROS scavenger that works as a glutathione precursor; $5 \mu \mathrm{M}$ ). In vivo, i.p. administration of $\mathrm{N}$-acetyl cysteine resulted in reduced ROS availability and subsequent hypothermia in the control animals. In the methamphetamine-treated mice, ROS delayed temperature increase and the temperature did not exceed $37.2^{\circ} \mathrm{C}$. The induction of ROS after methamphetamine treatment was attributed to the enhancement of activation of the mitochondrial respiratory chain, leading to the fast activation of UCP1 which is a critical mediator in PIH [Sanchez-Alavez et al., 2013; Chouchani et al., 2016]. These central and peripheral mediators further impact the diversity and population of the gut microbiome, which will be expanded upon in the following sections. 


\section{Role of the Intestinal Microbiome in the Regulation of Body Temperature and PIH}

The finding that the introduction of a Lactobacillus sp. to the digestive system of rats enhanced SNS activity and contributed to BAT thermogenesis suggested that the composition of the gut flora was physiologically relevant [Tanida et al., 2008]. Recently, more interest has developed regarding the role of the gut microbiome in thermogenesis. The depletion of the gut microbiome after treatment with multiple cocktails of antibiotics (ABX) led to an altered thermogenic response in mice [Li et al., 2019]. In their study, the effect of $\mathrm{ABX}$ treatment on thermogenesis was evaluated by an experiment of response to cold; it was shown that ABX-treated mice exposed to $4{ }^{\circ} \mathrm{C}$ for $48 \mathrm{~h}$ displayed impaired thermoregulation relative to specific pathogen-free (SPF) control mice. The ABX-treated mice also displayed a critically lower core body temperature at room temperature $\left(22^{\circ} \mathrm{C}\right)$. This alteration of thermogenesis was attributed mainly to blunting of the increase in expression of UCP1 and a decrease in the adipose tissue browning process, i.e., the conversion of white adipose tissue (WAT) to BAT. They also explored the possible role of butyrate regulation and thermogenesis by measuring $\mathrm{H}_{\mathrm{car} 2}$ (butyrate receptor) expression. Butyrate is a short-chain fatty acid (SCFA) that enhances energy expenditure and insulin sensitivity in mice [Gao et al., 2009]. The ABX-treated mice showed increased levels of $\mathrm{H}_{\text {car2 }}$ compared to controls [Li et al., 2019]. These findings are consistent with those of a previous study that suggested that cold stimulation increased the relative abundance of butyrate-producing bacteria, with a consequent increase in butyrate levels in the gut [Chevalier et al., 2015].

Another important thermogenesis mediator is brainderived neurotrophic factor (BDNF), the levels of which appear to be influenced by the gut microbiome [Bercik et al., 2011]. BDNF plays key roles in neurogenesis and energy regulation [Sharma and Johanson, 2007; Wang et al., 2010; Bercik et al., 2011]. BDNF regulates thermogenesis by increasing UCP1 mRNA expression in BAT, enhancing NE turnover, and elevating body temperature [Tsuchida et al., 2001; Sharma and Johanson, 2007; Wang et al., 2010]. The direct link between gut microbiome and BDNF levels remains poorly understood.

The potentially significant role of the gut microbiome in thermogenesis led our laboratory to investigate its potential role in PIH. Ridge et al. [2019] demonstrated that $\mathrm{ABX}$ treatment for 14 days prior to MDMA treatment in rats resulted in an alteration of the gut microbiome and

The Microbiome and Drug-Induced

Hyperthermia diminished MDMA-mediated hyperthermia. The critical mediators of PIH were also altered in the ABX treatment group prior to MDMA treatment, with decreased UCP1 and TGR5 expression levels in the BAT and SKM and a decreased UCP3 expression level in the SKM relative to non-ABX-treated MDMA-treated rats.

One strategy to investigate the role of the gut microbiome in host physiology is fecal microbial transplant technique (FMT) [Manichanh et al., 2010; Cui et al., 2016; Kelly et al., 2016]. We recently used FMT to investigate the possible role of the gut microbiome in methyloneinduced hyperthermia and tolerance to this hyperthermia [Goldsmith et al., 2020]. In this study, male rats were treated with methylone $(10 \mathrm{mg} / \mathrm{kg}$ s.c.) weekly, until tolerance to methylone-induced hyperthermia developed (in week 5), with control animals receiving saline for the same period. After the development of tolerance, bidirectional FMT was performed. We performed the FMT procedure for a period of 1 week following the fifth weekly methylone dose, and observed that the FMT from the saline-treated group to the tolerant group attenuated the tolerance response and restored hyperthermia to the latter. Furthermore, the reciprocal FMT from the methylone-treated group to the saline-treated control group was seen to induce tolerance to hyperthermia in this group after methylone administration; this was their very first methylone treatment. These observations were consistent with measurements of NE levels and UCP1, UCP3, and TGR5 expression levels in the BAT of both groups. After FMT, methylone-treated rats showed increased levels of NE and UCP1, UCP3, and TGR5 expression levels in the BAT and decreased expression levels of UCP 3 and TGR5 in the SKM. The metagenomic analysis of the gut microbiome before and after FMT revealed significant alterations in the composition and relative abundance of 2 classes of Proteobacteria (Gammaproteobacteria and Alphaproteobacteria) and in the firmicute class Erysipelotrichales [Goldsmith et al., 2020]. These findings further emphasize the critical role of the gut microbiome in PIH and tolerance, and the possible reshaping of the gut microbiome as a result of drug challenge.

\section{Intestinal Bacteria, NE, and Sympathomimetic Agents}

As noted above, numerous studies over the past decade have suggested an association between the central and the enteric nervous systems, i.e., a "gut-brain axis." Initial studies found that germ-free (GF) mice showed 
Fig. 3. Gut-brain communication and phenethylamine-induced hyperthermia (PIH). The gut-brain axis modulates physiological responses to various agents. This bidirectional interaction includes both endocrine and immunological signaling pathways. There are multiple routes by which the microbiome contributes to this signaling. Some bacteria locally produce neurotransmitters, including: norepinephrine (NE), dopamine (DA), epinephrine (Epi), and serotonin (5-HT). Fermentation reactions by other bacteria generate short-chain fatty acids (SCFAs), stimulating local 5-HT production through interaction with FFA receptors (FFARs) on epithelial enteroendocrine cells. These hormones potentially interact with adipose tissue (dotted red line). Intestinal flora directly stimulate cytokine production via the activation of Tolllike receptors (TLRs) and other components of the mucosal immune system. Together with hormones, these signals communicate with the brain. Alteration of microbiotia composition by phenethylamine stimulation (indicated by red arrow) potentially drives adaptive modulation of PIH. Figure generated using BioRender.

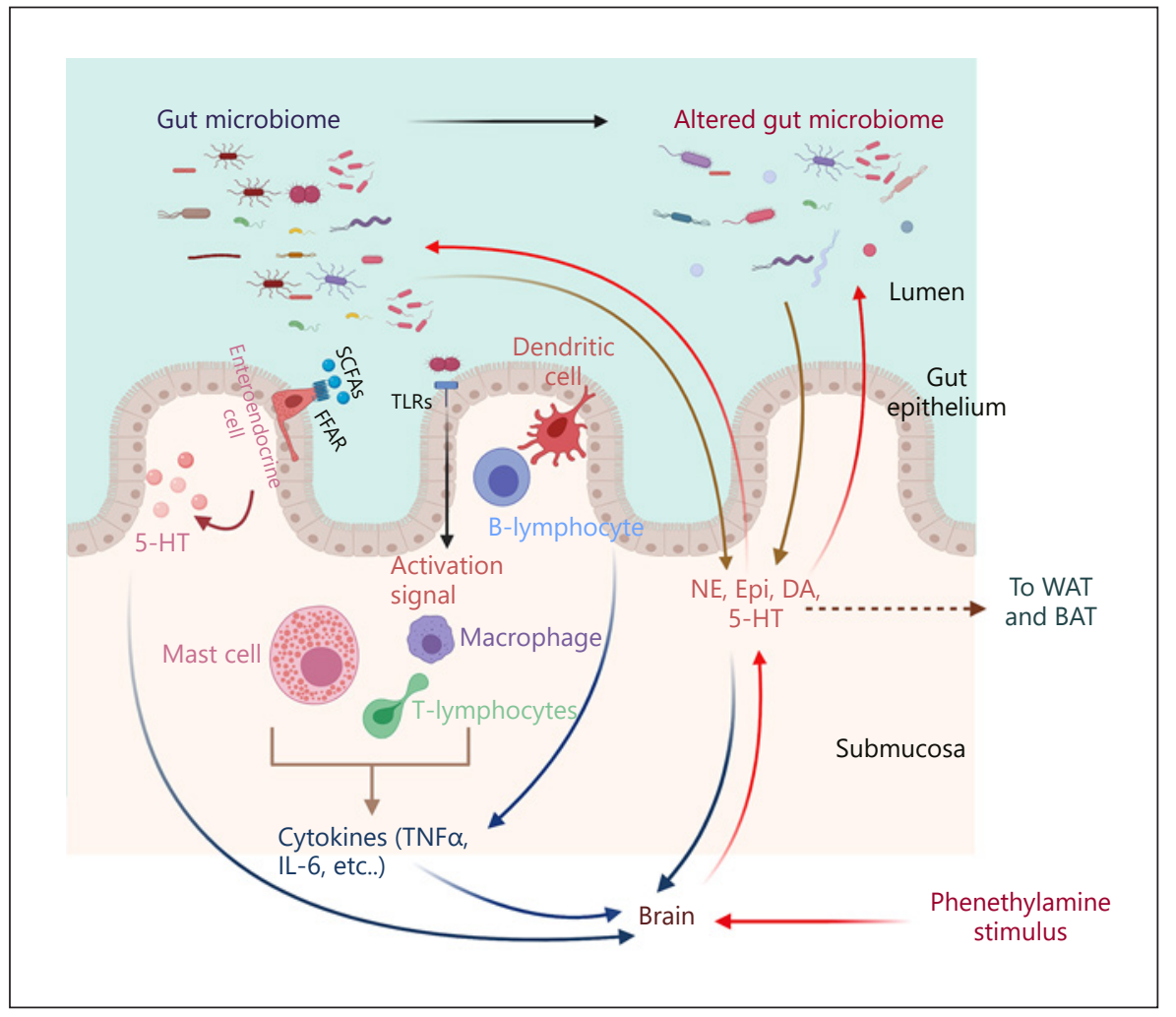

increased hormonal responses to handling stress, suggesting that the presence or absence of gut flora has an influence on the hypothalamic-pituitary-adrenal (HPA) axis [Sudo et al., 2004]. Subsequently, gut-resident bacteria were shown to engage in a dialogue with the CNS by influencing the endocrine, autonomic, and immune systems [Cryan and Dinan, 2012]. Thus, in addition to influencing the digestive system, microbial imbalances ("dysbiosis") are also associated with a variety of extraintestinal disorders including, but not limited to, Parkinson's disease [Sampson et al., 2016], Alzheimer's disease [Sochocka et al., 2019], depression [Lach et al., 2018] and metabolic diseases such as type II diabetes [Zhou et al., 2019].

Given its apparent ability to crosstalk with the neuroendocrine and immunological systems, it is not surprising that the gut microbiome influences behavioral responses to alcohol and psychoactive drugs such as cocaine [Bercik et al., 2011; Kiraly et al., 2016; Lowe et al., 2018]. The gut microbiome may therefore contribute to the responses to other pharmacological agents; indeed, recent studies indicate that MDMA and phenethylamine derivatives (e.g., synthetic cathinones) can influence the composition of the gut microbiome, and thus its metabolic potential [Ridge et al., 2019; Angoa-Pérez et al., 2020]. The evidence to date implicates the production of bacterial metabolites (e.g., SCFAs and secondary bile acids) and the local production of cytokines and neurotransmitters [Martin et al., 2018] as potential mediators for information exchange between the gut flora and host systems (Fig. 3).

Neurotransmitters are major components of the "gutbrain axis" that moderate host behavioral responses as well as the bidirectional communication between the gut and the CNS. Major catecholamines such as DA and NE regulate different types of functions associated with host nervous and alimentary systems [Eisenhofer et al., 2004]. These neurotransmitters also act on at least some gutresident bacteria. In vitro studies indicate that NE signaling can activate the expression of virulence genes in enterohaemorrhagic Escherichia coli strains [Clarke et al., 2006; Asano et al., 2012]. According to Clarke et al. [2006], the QseC adrenergic receptor aids cross-kingdom signaling by sensing $\mathrm{NE}$ and epinephrine (Epi). In addition, Sudo [2019] noted that catecholamines enhanced the proliferative capacities of certain Gram-negative bacterial species. These findings highlighted the effect of $\mathrm{NE}$ and other catecholamines on a limited set of bacterial species in vitro, but the overall effect on microbial populations was unclear. 
To address this, Angoa-Pérez et al. [2020] examined the effects of different sympathomimetic agents on the gut microbiome. They found that each of 4 distinct synthetic cathinones and amphetamines (mephedrone, methamphetamine, methcathinone, and 4-methylmethaphetamine) exerted differential effects on the gut microbiome. Metagenomic analysis of the gut flora identified a decrease in the relative abundance of Bifidobacteriales 7 days after administration of all the drugs. The order Bifidobacteriales includes strains that produce $\gamma$-amino butyric acid (GABA), an inhibitory neurotransmitter that induces BAT dysfunction and the downregulation of UCP1 expression [Barrett et al., 2012; Ikegami et al., 2018]. These findings suggest a putative role of the gut microbiome in PIH tolerance. It can thus be considered that the differences in hyperthermic responses to methylone in male and female rats, as shown by Goldsmith et al. [2019], might also be modulated by certain gut bacterial families. Angoa-Pérez et al. [2020] also found an increase in Enterobacterales levels $24 \mathrm{~h}$ after methamphetamine treatment, consistent with the observations of Ridge et al. [2019] who demonstrated enrichment of Proteus sp. in the cecal flora after acute administration of MDMA. Proteus is an important member of the order Enterobacterales [Adeolu et al., 2016]. Members of the genus Proteus are known to produce a urease enzyme that hydrolyzes urea into carbon dioxide and ammonia [Jones and Mobley, 1988]. According to Halpin and Yamamoto [2012], ammonia is chiefly responsible for oxidative damage to dopaminergic and serotonergic neurons in the brains of rats following methamphetamine exposure. These findings are consistent with the possible role of phenethylamines in facilitating the growth of bacterial species that aid drug-induced neurotoxicity.

Bacterial species residing in the gut environment have also been associated with the production of neurotransmitters [Strandwitz, 2018]. Local production of 5-HT by intestinal bacteria has the potential to contribute to the regulation of enzyme secretion in the gastrointestinal tract and global energy homeostasis [Mittal et al., 2017]. Additionally, Crane et al. [2015] showed 5-HT to be critical for BAT-associated thermogenesis. According to the studies conducted by Nash [1990] and Hagino et al. [2011], MDMA-induced 5-HT release enhances DA release by stimulating $5-\mathrm{HT}_{2}$ receptors, thereby facilitating thermogenesis. These results were consistent with the finding that phenethylamine administration increases 5-HT levels.

As noted above, production of 5-HT from its precursor tryptophan can be carried out by gut bacterial en- zymes; for example, certain strains of Lactobacillus sp. and Lactococcus sp. produce enzymes that aid the conversion of tryptophan to 5-HT [Özoğul et al., 2012]. As indicated in Figure 3, 5-HT production in the gut is mediated by SCFAs [Evans et al., 2013]. SCFAs are the end-products of the fermentation of long-chained carbohydrates and dietary fibers by the anaerobic intestinal bacteria [den Besten et al., 2013]. According to Lin et al. [2012], SCFAs play a major role in host energy homeostasis. They have also been noted to aid UCP-mediated thermogenesis [den Besten et al., 2013; Clark and Mach, 2017]. Lin et al. [2012] found that SCFAs have a high affinity for FFA receptors (FFARs). It has been suggested that SCFAs bind to FFARs present on enteroendocrine cells, thereby contributing to the release of 5-HT in the gut [Reigstad et al., 2015] (highlighted in Fig. 3).

In addition to 5-HT and GABA, certain bacterial strains are known to facilitate catecholamine production in vitro [Clarke et al., 2014; Strandwitz, 2018]. The production of NE has been associated with Bacillus sp., E. coli, Serratia marcescens, and Proteus vulgaris [Tsavkelova et al., 2000]. The ability of Proteus sp. to produce NE corroborates the observations in the study by Ridge et al. [2019], suggesting the possibility that the increased relative levels of Proteus enhances the NE turnover, which, along with MDMA, aids UCP-mediated thermogenesis. While this is an interesting speculation, it is likely that this and other phenotypic changes associated with microbiota dynamics are the product of multiple interactions between microbial populations and their host, the exploration of which has only begun.

\section{Sympathomimetic-Induced Changes in Gene Expression Associated with Hyperthermia and Potentially Linked to the Microbiome}

While microbes in the gut are known to produce different neurotransmitters that modulate thermogenic responses, the molecular mechanisms remain elusive. To understand the role of gut microbiota in UCP-mediated thermogenesis, it is important to understand the regulation of UCPs in the cell.

$\mathrm{UCP} 1$ is found extensively in the BAT, where regulation of its expression takes place at different levels. At the transcriptional level, the expression of UCP1 depends on the regulatory region present in the $5^{\prime}$ non-coding region of the UCP1 gene (Fig. 4). Transcription of UCP1 is upregulated when cAMP mediates protein kinase A (PKA) phosphorylation of the CAMP response-element binding 
Fig. 4. Illustration of 2 regulatory regions in the UCP1 gene, along with different mediators for transcription regulation. The 2 regions include the proximal region close to the transcription start site (TSS), and the distal enhancer region away from the TSS. All the factors, except RIP140, are activating factors for UCP1 transcription. PGC$1 \alpha$, proliferator-activated receptor- $\gamma$ coactivator 1- $\alpha$; RAR, retinoic acid receptor; RXR, retinoid X receptor; TR, thyroid hormone receptor; PPAR, peroxisome-proliferator activated receptor; CREB, cAMP-responsive element binding protein; ATF-2, activating transcription factor-2; Zfp516, zinc finger protein 516; RIP140, receptorinteracting protein 140 .

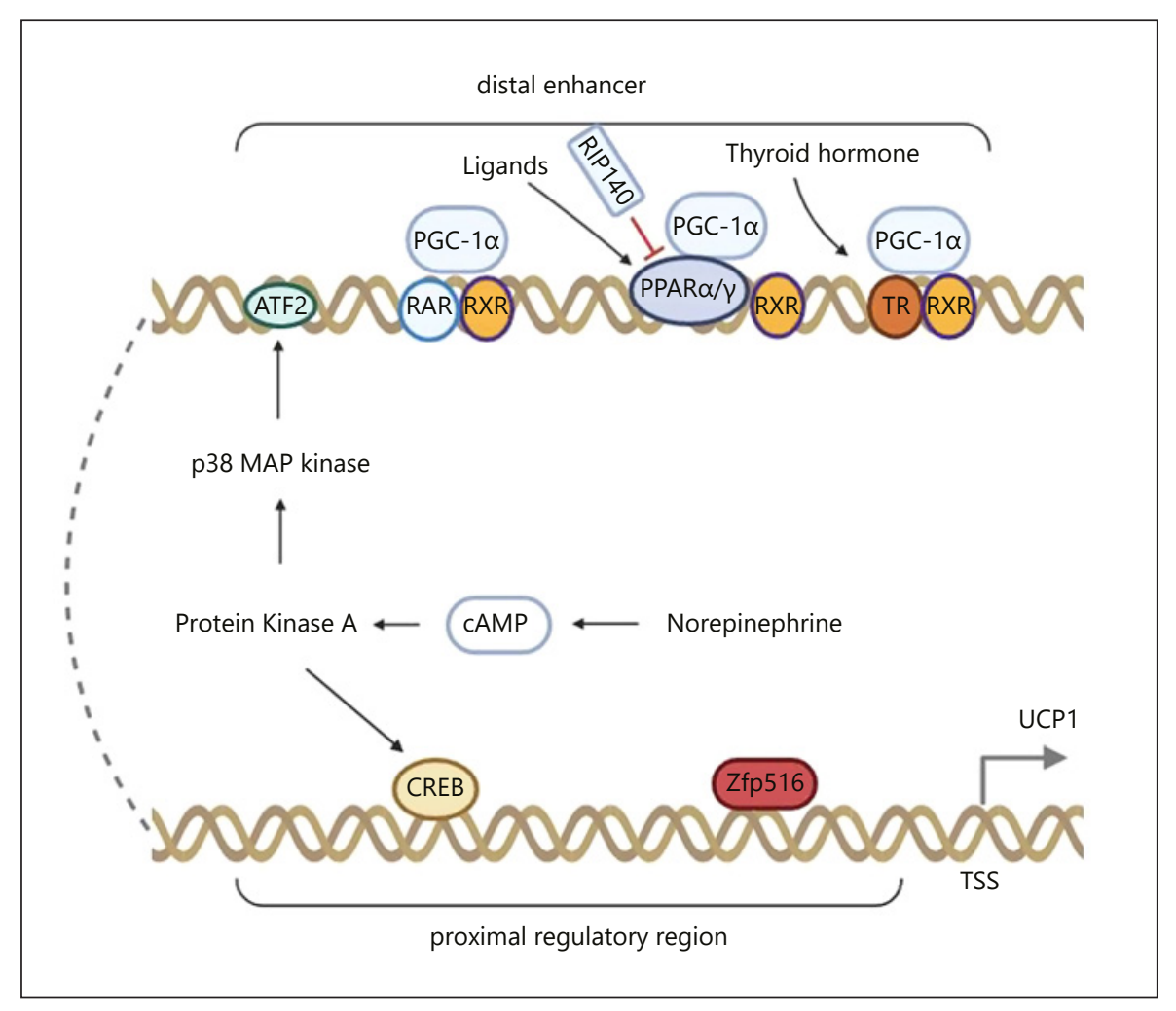

protein (CREB) bound to the CRE-binding site in the proximal regulatory region of the UCP1 gene [Kozak et al, 1994; Yubero et al., 1998]. In response to cold induction, browning of WAT is the result of the activation of $U C P 1$ expression by the transcription factor zinc finger protein-516 (Zfp516) that binds to the proximal region of the UCP1 gene promoter [Dempersmier et al., 2015].

BAT-specific transcription of the UCP1 gene is also attributed to the enhancer region [Kozak et al., 1994] that contains response elements for nuclear hormone receptors such as peroxisome proliferator-activated receptor $\alpha$ (PPARa) and PPAR $\gamma$. Thyroid receptor (TR) dimerizes with retinoid $X$ receptor (RXR) to control the transcription of UCP1 in response to specific ligands [Rabelo et al., 1995; Sears et al., 1996; Barberá et al., 2001; Villarroya et al., 2007]. NE action is also known to elicit cAMP-mediated signaling that involves the 338 MAP kinase-mediated phosphorylation of activating transcription factor-2 (ATF-2) that binds at the upstream site in the enhancer region, thereby controlling the transcription of the UCP 1 gene [Robidoux et al., 2005].

In addition to transcription activators, chemical mediators that repress $U C P 1$ transcription have also been reported. Receptor-interacting protein 140 (RIP140) was found to repress $U C P 1$ gene transcription by interaction via PPARa and PPAR $\gamma$, that bind nuclear receptors in the enhancer region of the UCP1 gene [Leonardsson et al., 2004]. Epigenetic control of UCP1 transcription by RIP140 has also been reported, whereby the protein acts as a scaffold for the assembly of DNA- and histone-methyltransferases in the enhancer region, catalyzing the methylation of $\mathrm{CpG}$ residues and histones, and leading to gene repression [Kiskinis et al., 2007]. Conversely, expression of UCP3 is highly specific to SKM and is expressed only slightly in the human heart [Vidal-Puig et al., 1997]. Transcription of UCP3 has also been detected in the BAT of rodents [Boss et al., 1997]. Regulation of UCP3 in mouse skeletal muscle has been shown to be caused by myogenic regulatory factor (MyoD), that acts on the promoter region of the gene [Kim et al., 2007].

PPAR $\gamma$, PPAR $\delta$, and the PPAR $\gamma$ coactivator- $1 \alpha$ (PGC$1 \alpha)$ are involved in the upregulation of UCP 3 transcripts via an AMPK-mediated pathway [Villarroya et al., 2007; Marin et al., 2017]. The expression of UCP3 is also regulated by thyroid hormone [Solanes et al., 2005; de Lange et al., 2007], glucocorticoids [Amat et al., 2007], and vitamin $\mathrm{D}_{3}$ [Fan et al., 2016]. Downregulation of UCP3 has been associated with the activation of the JAK2/STAT3 signaling pathway [Liu et al., 2012] and estrogen [Nagai et al., 2016]. 


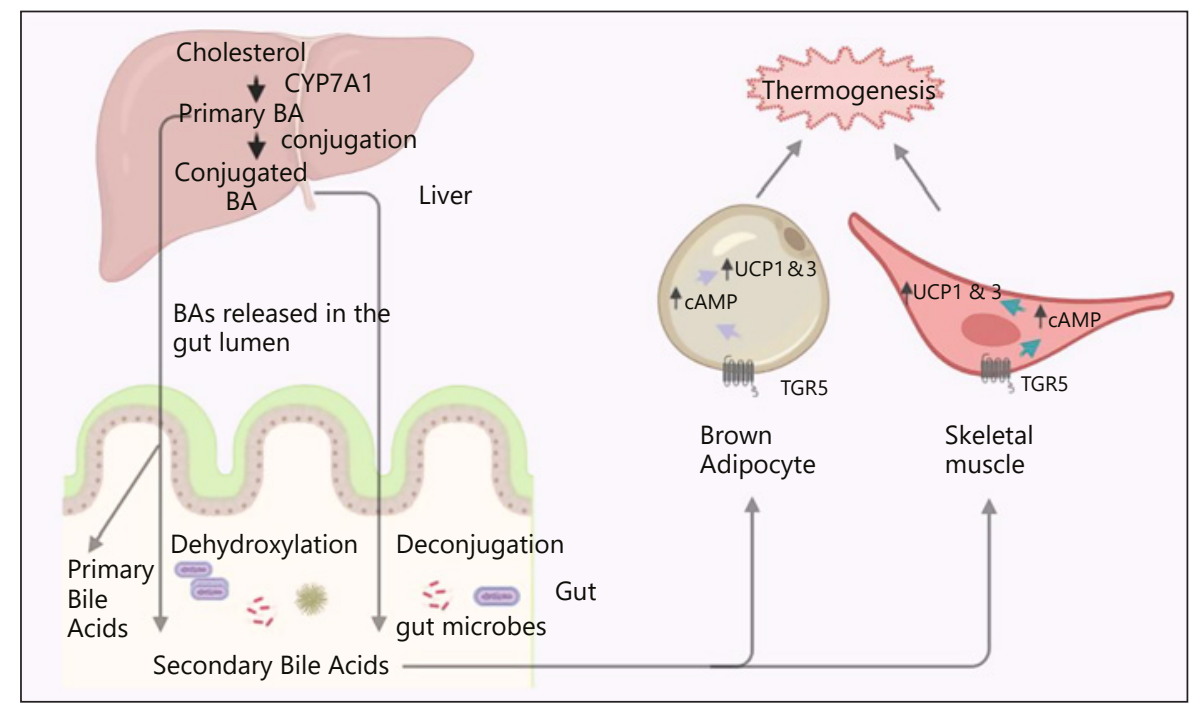

Fig. 5. Schematic of the bile acid conversion in the gut by microbes and its role in thermogenesis. Cholesterol in the liver is converted into primary bile acids by enzyme CYP7A1, which are then conjugated into the amino acids glycine and taurine to form conjugated bile acids. These conjugated bile acids are released in the duodenum and are further converted into secondary bile acids via deconjugation by gut microbes. Gut microbes also aid the dehy- droxylation of unconjugated primary bile acids released in the gut into secondary bile acids that bind to TGR5 receptors present in the brown adipocytes and muscle cells, thereby initiating a Gprotein-coupled receptor (GPCR) signal transduction pathway, increasing the level of cAMP that activates the expression of UCP1 and UCP3 in the mitochondrion, and dissipating energy in the form of heat.
Dysbiosis following substance abuse has been reported in several studies. This section focuses on describing the potential roles of gut microbes in hyperthermia via the TGR5 pathway. As noted above, bile acids activate TGR5mediated signaling, which plays a role in PIH. TGR5 homozygous knockout mice showed significantly greater expression of the bile acid-modifying enzyme, cholesterol $7 \alpha$ hydroxylase (CYP7A1) than found in WT mice. However, the concentration of bile acids was not increased, suggesting that other mechanisms may be involved in the regulation of bile acids [Maruyama et al., 2006]. In mammals, primary bile acids are produced in the liver. As they travel through the intestinal tract, these primary bile acids are often converted to secondary bile acids by the gut microbiota.

In humans, primary bile acids are synthesized through the cytochrome $\mathrm{P} 450$ pathway, while secondary bile acids are the product of the deconjugation/dehydroxylation of primary bile acids by gut microbes (Fig. 5) [Ridlon et al., 2006; Winston and Theriot, 2020]. High levels of bile acids are toxic to both the host cells and the gut microbes, with regulation by feedback control involving the conversion of primary bile acids to secondary bile acids by the gut microbes. Additionally, gut microbes use bile acids to induce the expression of antimicrobial peptides, indicat- ing that the presence of bile acids could be a survival condition for microbes in the gut [Inagaki et al., 2006].

Numerous studies supporting the role of gut microbes in bile acid regulation have been reported. In GF- or $\mathrm{ABX}$-treated mice or rats, the bile acid pool consists mainly of primary bile acids [Wostmann, 1973; Sayin et al., 2013; Selwyn et al., 2015]. Firmicute bacteria in the genera Clostridium and Eubacterium isolated from humans are known to metabolize bile acids and use them as electron acceptors [Kitahara et al., 2001; Ridlon et al., 2006, 2014]. Members of these genera share a bile-acidinduced (bai) operon that encodes for the transformation of primary bile acids into secondary bile acids via dehydroxylation of mono- and di-hydroxyl bile acids [Ridlon et al., 2016]. Additionally, members of the class Erysipelotrichales were identified as key moderators of the bile acid pools in the gut by Labbé et al. [2014]. The impact of the gut microbiota on bile acid composition was demonstrated in mice receiving Clostridium scindens. In this study, the levels of secondary bile acids were significantly increased after 2 weeks of treatment, suggesting the role of the gut microbiota in regulating bile acid synthesis [Ridlon et al., 2016; Wei et al., 2020]. Secondary bile acids generated by dehydroxylation have been noted to be more effective activators of TGR5 than primary bile acids 
[Donepudi et al., 2017]. Because TGR5 is a key regulator of $\mathrm{PIH}$, this is consistent with a potential role of gut microbes in TGR5-mediated hyperthermia.

Because many dietary carbohydrates from plants cannot be digested by human enzymes, we rely on the gut microbiota to produce the necessary enzymes that metabolize carbohydrates into SCFAs. The primary gut microbial-derived SCFAs are acetates, propionates, and butyrates [Patterson et al., 2014; Flint et al., 2015]. In GF mice, SCFAs are significantly lower than those in mice with normal resident gut flora [Høverstad and Midtvedt, 1986]. In mammals, SCFAs have been shown to affect the host through multiple mechanisms including: (1) acting as signal transduction molecules via GPCRs [Maslowski, et al., 2009; Patterson et al., 2014], (2) serving as substrates for the synthesis of longer-chain fatty acids and ketone bodies [Macfarlane and Macfarlane, 2003; Flint et al., 2015], (3) inhibiting the growth of enteric pathogens [Macfarlane and Macfarlane, 2003; Ashida et al., 2011], and (4) regulating histone modifications of host tissues [Krautkramer et al., 2016].

The function of SCFAs as signal molecules occurs via interactions with GPCRs. Binding of SCFAs to FFAR2 (also known as Gpr43) resulted in the regulation of immune and inflammatory responses [Maslowski et al., 2009]. GF mice, which express little or no SCFAs, show dysregulation of inflammatory responses. When the gut of GF mice was recolonized with microbiota from the feces of conventionally raised mice, a significant reduction in inflammation was observed, suggestive of a role for the microbiota in the regulation of inflammatory processes in the gut [Maslowski et al., 2009]. TGR5 has also been implicated in immune response as an anti-inflammatory protein. Upon activation, it may signal the brain via neural circuits that lead to the regulation of immune response as well as thermogenesis. The most potent activators are propionate, butyrate, and pentanoate, while acetate is a poor activator [Brown et al., 2003; Le Poul et al., 2003; Kim et al., 2013].

A recent study by Kimura et al. [2020] using pregnant mice bred under SPF and GF conditions demonstrated that the maternal microbiota specifically generated SCFAs that interacted with GPR41 and GPR43 and influenced the prenatal development of the metabolic and neural systems of the offspring. This supports a role for microbial-derived SCFAs of pregnant mice to act as environmental cues to fine-tune energy homeostasis in their offspring. A role for SCFAs in inhibiting the growth of enteric pathogens was also suggested. In both GF and $\mathrm{ABX}$ treatment models, reduced production of antimi- crobials in the small intestine was observed, indicating that colonization of gut microbes is essential for the activation and production of antimicrobial compounds [Ivanov et al., 2008; Ismail et al., 2011].

Acetate produced by commensal bacteria in the genus Bifidobacterium, known to exhibit various probiotic effects, was reported to promote the defense of mouse epithelial cells against enterohemorrhagic E. coli O157:H7 [Fukuda et al., 2011]. Butyrate and propionate repressed the expression of bacterial virulence genes in Salmonella [Gantois et al., 2006; Boyen et al., 2008]. Lactobacillus johnsonii L531 was reported to reduce the population of pathogenic Salmonella infantis in both the feces and systemic organs in piglets, possibly via SCFAs [He et al., 2019]. Several lines of evidence support this hypothesis. First, L. johnsonii L531 produces high levels of SCFAs (butyric, acetic, and lactic acid) in vitro [He et al., 2019]. Second, the severity of the salmonella infection was negatively correlated with the levels of both total SCFAs and butyrate in the cecum [Borton et al., 2017]. These data indicate that the probiotic microbes stimulate the immune response of the host cells as well as reduce the growth of the pathogenic microbes.

The impact of SCFAs on the epigenetic regulation of host cells has been reported since the 1970s. Butyrate was reported to be a strong inhibitor of histone deacetylases [Cousens et al., 1979], that catalyze the removal of acetyl groups from $\geq 1$ lysine amino acids of histones, enabling DNA to associate more tightly with histones, thus repressing gene expression. Reducing the relative levels of butyrate-forming bacteria, including the Bacteroides fragilis population, resulted in increased histone deacetylase-3 activity [Noureldein et al., 2020], suggesting that butyrate functions as a histone deacetylase inhibitor. A study performed on mice found that a combination of diet and the type of gut microbiota regulated global histone acetylation and methylation in multiple host tissues in a diet-dependent manner [Arpaia et al., 2013; Krautkramer et al., 2016]. Supplementation of GF mice with SCFAs was sufficient to change the state of the chromatin and transcriptional responses of host epigenetic programming [Arpaia et al., 2013; Kasubuchi et al., 2015; Krautkramer et al., 2016].

The binding of histone demethylase Jhdm2a to the PPAR-responsive element of the UCP1 gene leads to reduced demethylation of lysine 9 of histone $\mathrm{H} 3$ (H3K9me2) at the PPRE, and activates UCP1 expression [Tateishi et al., 2009]. Knockout mice that lacked a H3K9specific histone demethylase (JHDM2a-/-) displayed rapidly induced hypothermia and the expression of UCP1 
was repressed in their SKM [Inagaki et al., 2009; Tateishi et al., 2009; Aoyama et al., 2010]. Because SCFAs can regulate host cell activity via epigenetic influences, it is possible that the decreased expression of UCP1 protein in these knockout mice was caused by histone modifications induced by SCFAs.

DNA methylation of the promoter region of a gene is one mechanism of epigenetic gene regulation. While the role of the gut microbiota in DNA methylation in PIH has been under-studied, the role of SCFAs in DNA methylation was demonstrated by Remely et al. [2014], who explored the contribution of the microbiota to epigenetic regulation in obese and type 2 diabetes patients relative to a lean control group. Analysis of methylation in the promoter region of a GPCR, the FFAR3 gene, showed that the lean group had a significantly higher degree of methylation and was accompanied by a significant correlation with a lower body mass index and a lower amount of the butyryl-CoA:acetate CoA-transferase gene of Clostridium spp. Taken together, this study demonstrated that butyrate is partially responsible for regulating FFAR3 via DNA methylation. In the intestinal epithelial cells of GF mice, methylation of the Toll-like receptor 4 gene (TLR4) was significantly lower than that of conventional mice and associated with a strong loss of TLR4 activity. These data indicate that the gut microbiota contributes to the regulation of intestinal inflammation and the maintenance of intestinal symbiosis via epigenetic modification [Takahashi et al., 2011]. While the role of the gut micro- biota in histone modifications has been identified in several studies, their contribution to DNA methylation is less well established.

\section{Conclusion}

This review highlighted the general pathways contributing to the induction and maintenance of PIH. These include both peripheral and central mediators that are altered mainly due to SNS activation upon phenethylamine treatment. Interestingly, the modulation of the gut microbiome observed in animal models displaying PIH suggests a possible bidirectional communication between the gut and brain that may be a significant determinant of PIH. To date, only a few studies have examined the role of the gut-brain axis in PIH, and much research is still needed to further enhance our understanding of the role of the microbiome in PIH.

\section{Conflict of Interest Statement}

The authors have no conflicts of interest to declare.

\section{Author Contributions}

All 7 authors worked in a collaborative fashion in the conceptualization, writing and editing of this review article.

\section{References}

Adeolu M, Alnajar S, Naushad S, S Gupta R. Genome-based phylogeny and taxonomy of the 'Enterobacteriales': proposal for Enterobacterales ord. nov. divided into the families Enterobacteriaceae, Erwiniaceae fam. nov., Pectobacteriaceae fam. nov., Yersiniaceae fam. nov., Hafniaceae fam. nov., Morganellaceae fam. nov., and Budviciaceae fam. nov. Int J Syst Evol Microbiol. 2016 Dec;66(12):557599.

Amat R, Solanes G, Giralt M, Villarroya F. SIRT1 is involved in glucocorticoid-mediated control of uncoupling protein-3 gene transcription. J Biol Chem. 2007 Nov;282(47):3406676.

Angoa-Pérez M, Zagorac B, Winters AD, Greenberg JM, Ahmad M, Theis KR, et al. Differential effects of synthetic psychoactive cathinones and amphetamine stimulants on the gut microbiome in mice. PLoS One. 2020 Jan; 15(1):e0227774.

Aoyama M, Kotani J, Usami M. Butyrate and propionate induced activated or non-activated neutrophil apoptosis via HDAC inhibitor activity but without activating GPR-41/GPR-43 pathways. Nutrition. 2010 Jun;26(6):653-61. Armenian P, Mamantov TM, Tsutaoka BT, Gerona RR, Silman EF, Wu AH, et al. Multiple MDMA (Ecstasy) overdoses at a rave event: a case series. J Intensive Care Med. 2013;28(4): 252-8.

Arpaia N, Campbell C, Fan X, Dikiy S, van der Veeken J, deRoos P, et al. Metabolites produced by commensal bacteria promote peripheral regulatory T-cell generation. Nature. 2013 Dec;504(7480):451-5.

Asano Y, Hiramoto T, Nishino R, Aiba Y, Kimura $\mathrm{T}$, Yoshihara K, et al. Critical role of gut microbiota in the production of biologically active, free catecholamines in the gut lumen of mice. Am J Physiol Gastrointest Liver Physiol. 2012 Dec;303(11):G1288-95.

Ashida H, Ogawa M, Kim M, Mimuro H, Sasakawa C. Bacteria and host interactions in the gut epithelial barrier. Nat Chem Biol. 2011 Dec; $8(1): 36-45$
Bae YS, Kang SW, Seo MS, Baines IC, Tekle E, Chock PB, et al. Epidermal growth factor (EGF)-induced generation of hydrogen peroxide. Role in EGF receptor-mediated tyrosine phosphorylation. J Biol Chem. 1997 Jan; 272(1):217-21.

Banks ML, Worst TJ, Rusyniak DE, Sprague JE. Synthetic cathinones and amphetamine analogues. What's the rave about? J Med. 2014; 46(5):632-42.

Barberá MJ, Schlüter A, Pedraza N, Iglesias R, Villarroya F, Giralt M. Peroxisome proliferator-activated receptor $\alpha$ activates transcription of the brown fat uncoupling protein-1 gene. A link between regulation of the thermogenic and lipid oxidation pathways in the brown fat cell. J Biol Chem. 2001 Jan;276(2): 1486-93.

Barrett E, Ross RP, O'Toole PW, Fitzgerald GF, Stanton C. $\gamma$-Aminobutyric acid production by culturable bacteria from the human intestine. J Appl Microbiol. 2012 Aug;113(2):4117.
The Microbiome and Drug-Induced Hyperthermia
Brain Behav Evol 2020;95:256-271 DOI: $10.1159 / 000512098$ 
Bercik P, Denou E, Collins J, Jackson W, Lu J, Jury $\mathrm{J}$, et al. The intestinal microbiota affect central levels of brain-derived neurotropic factor and behavior in mice. Gastroenterology. 2011 Aug;141(2):599-609.

Boivin B, Yang M, Tonks NK. Targeting the reversibly oxidized protein tyrosine phosphatase superfamily. Sci Signal. 2010 Aug;3(137):pl2.

Borek HA, Holstege CP. Hyperthermia and multiorgan failure after abuse of "bath salts" containing 3,4-methylenedioxypyrovalerone. Ann Emerg Med. 2012 Jul;60(1):103-5.

Borton MA, Sabag-Daigle A, Wu J, Solden LM, O'Banion BS, Daly RA, et al. Chemical and pathogen-induced inflammation disrupt the murine intestinal microbiome. Microbiome. 2017 Apr;5(1):47.

Boss O, Samec S, Paoloni-Giacobino A, Rossier C, Dulloo A, Seydoux J, et al. Uncoupling protein-3: a new member of the mitochondrial carrier family with tissue-specific expression. FEBS Lett. 1997 May;408(1):39-42.

Boyen F, Haesebrouck F, Vanparys A, Volf J, Mahu M, Van Immerseel F, et al. Coated fatty acids alter virulence properties of Salmonella Typhimurium and decrease intestinal colonization of pigs. Vet Microbiol. 2008 Dec; 132(3-4):319-27.

Bravo JA, Forsythe P, Chew MV, Escaravage E, Savignac HM, Dinan TG, et al. Ingestion of Lactobacillus strain regulates emotional behavior and central GABA receptor expression in a mouse via the vagus nerve. Proc Natl Acad Sci USA. 2011 Sep;108(38):16050-5.

Brown AJ, Goldsworthy SM, Barnes AA, Eilert MM, Tcheang L, Daniels D, et al. The Orphan G protein-coupled receptors GPR41 and GPR43 are activated by propionate and other short chain carboxylic acids. J Biol Chem. 2003 Mar;278(13):11312-9.

Brown PL, Kiyatkin EA. Brain hyperthermia induced by MDMA (ecstasy): modulation by environmental conditions. Eur J Neurosci. 2004 Jul;20(1):51-8.

Campbell GA, Rosner MH. The agony of ecstasy: MDMA (3,4-methylenedioxymethamphetamine) and the kidney. Clin J Am Soc Nephrol. 2008 Nov;3(6):1852-60.

Campbell SE, Tandon NN, Woldegiorgis G, Luiken JJ, Glatz JF, Bonen A. A novel function for fatty acid translocase (FAT)/CD36: involvement in long chain fatty acid transfer into the mitochondria. J Biol Chem. 2004 Aug; 279(35):36235-41.

Cannon B, Nedergaard J. Brown adipose tissue: function and physiological significance. Physiol Rev. 2004 Jan;84(1):277-359.

Chevalier C, Stojanović O, Colin DJ, SuarezZamorano N, Tarallo V, Veyrat-Durebex C, et al. Gut microbiota orchestrates energy homeostasis during cold. Cell. 2015 Dec;163(6) 1360-74.

Chouchani ET, Kazak L, Jedrychowski MP, Lu GZ, Erickson BK, Szpyt J, et al. Mitochondrial ROS regulate thermogenic energy expenditure and sulfenylation of UCP1. Nature. 2016 Apr;532(7597):112-6.
Clark A, Mach N. The crosstalk between the gut microbiota and mitochondria during exercise. Front Physiol. 2017;8:319.

Clarke G, Stilling RM, Kennedy PJ, Stanton C, Cryan JF, Dinan TG. Minireview: Gut microbiota: the neglected endocrine organ. Mol Endocrinol. 2014 Aug;28(8):1221-38.

Clarke MB, Hughes DT, Zhu C, Boedeker EC, Sperandio V. The QseC sensor kinase: a bacterial adrenergic receptor. Proc Natl Acad Sci USA. 2006 Jul;103(27):10420-5.

Cousens LS, Gallwitz D, Alberts BM. Different accessibilities in chromatin to histone acetylase. J Biol Chem. 1979 Mar;254(5):1716-23.

Crane JD, Palanivel R, Mottillo EP, Bujak AL, Wang H, Ford RJ, et al. Inhibiting peripheral serotonin synthesis reduces obesity and metabolic dysfunction by promoting brown adipose tissue thermogenesis. Nat Med. 2015 Feb;21(2):166-72.

Cryan JF, Dinan TG. Mind-altering microorganisms: the impact of the gut microbiota on brain and behaviour. Nat Rev Neurosci. 2012 Oct;13(10):701-12.

Cui B, Li P, Xu L, Peng Z, Xiang J, He Z, et al. Stepup fecal microbiota transplantation (FMT) strategy. Gut Microbes. 2016 Jul;7(4):323-8.

de Lange P, Feola A, Ragni M, Senese R, Moreno M, Lombardi A, et al. Differential 3,5,3'-triiodothyronine-mediated regulation of uncoupling protein 3 transcription: role of Fatty acids. Endocrinology. 2007 Aug;148(8):406472 .

Dempersmier J, Sambeat A, Gulyaeva O, Paul SM, Hudak CS, Raposo HF, et al. Cold-inducible Zfp516 activates UCP1 transcription to promote browning of white fat and development of brown fat. Mol Cell. 2015 Jan;57(2):23546.

den Besten G, van Eunen K, Groen AK, Venema $\mathrm{K}$, Reijngoud DJ, Bakker BM. The role of short-chain fatty acids in the interplay between diet, gut microbiota, and host energy metabolism. J Lipid Res. 2013 Sep;54(9): 2325-40.

Dickinson BC, Huynh C, Chang CJ. A palette of fluorescent probes with varying emission colors for imaging hydrogen peroxide signaling in living cells. J Am Chem Soc. 2010 Apr; 132(16):5906-15.

Donepudi AC, Boehme S, Li F, Chiang JY. G-protein-coupled bile acid receptor plays a key role in bile acid metabolism and fasting-induced hepatic steatosis in mice. Hepatology. 2017 Mar;65(3):813-27.

Eisenhofer G, Kopin IJ, Goldstein DS. Catecholamine metabolism: a contemporary view with implications for physiology and medicine. Pharmacol Rev. 2004 Sep;56(3):331-49.

Evans JM, Morris LS, Marchesi JR. The gut microbiome: the role of a virtual organ in the endocrinology of the host. J Endocrinol. 2013 Aug; 218(3):R37-47.

Eyer F, Zilker T. Bench-to-bedside review: mechanisms and management of hyperthermia due to toxicity. Crit Care. 2007;11(6):236
Fan Y, Futawaka K, Koyama R, Fukuda Y, Hayashi $M$, Imamoto $M$, et al. Vitamin D3/VDR resists diet-induced obesity by modulating UCP3 expression in muscles. J Biomed Sci. 2016 Jul;23(1):56.

Flint HJ, Duncan SH, Scott KP, Louis P. Links between diet, gut microbiota composition and gut metabolism. Proc Nutr Soc. 2015 Feb; 74(1):13-22.

Fukuda S, Toh H, Hase K, Oshima K, Nakanishi $\mathrm{Y}$, Yoshimura K, et al. Bifidobacteria can protect from enteropathogenic infection through production of acetate. Nature. 2011 Jan; 469(7331):543-7.

Gantois I, Ducatelle R, Pasmans F, Haesebrouck F, Hautefort I, Thompson A, et al. Butyrate specifically down-regulates salmonella pathogenicity island 1 gene expression. Appl Environ Microbiol. 2006 Jan;72(1):946-9.

Gao Z, Yin J, Zhang J, Ward RE, Martin RJ, Lefevre $M$, et al. Butyrate improves insulin sensitivity and increases energy expenditure in mice. Diabetes. 2009 Jul;58(7):1509-17.

Goldsmith R, Aburahma A, Pachhain S, Choudhury SR, Phuntumart V, Larsen R, et al. Fecal microbial transplant abates tolerance to methylone-induced hyperthermia. Sci Rep. 2020. E-pub ahead of print.

Goldsmith R, Pachhain S, Choudhury SR, Phuntumart V, Larsen R, Sprague JE. Gender differences in tolerance to the hyperthermia mediated by the synthetic cathinone methylone. Temperature. 2019 Aug;6(4):334-40.

Guerra-Ordaz AA, Molist F, Hermes RG, Gómez de Segura A, La Ragione RM, Woodward MJ, et al. Effect of inclusion of lactulose and Lactobacillus plantarum on the intestinal environment and performance of piglets at weaning. Anim Feed Sci Technol. 2013 Oct; 185(3): $160-8$.

Hagino Y, Takamatsu Y, Yamamoto H, Iwamura T, Murphy DL, Uhl GR, et al. Effects of MDMA on extracellular dopamine and serotonin levels in mice lacking dopamine and/or serotonin transporters. Curr Neuropharmacol. 2011 Mar;9(1):91-5.

Halpin LE, Yamamoto BK. Peripheral ammonia as a mediator of methamphetamine neurotoxicity. J Neurosci. 2012 Sep;32(38):13155-63.

He T, Zhu YH, Yu J, Xia B, Liu X, Yang GY, et al. Lactobacillus johnsonii L531 reduces pathogen load and helps maintain short-chain fatty acid levels in the intestines of pigs challenged with Salmonella enterica Infantis. Vet Microbiol. 2019;230:187-94.

Herin DV, Liu S, Ullrich T, Rice KC, Cunningham KA. Role of the serotonin 5-HT2A receptor in the hyperlocomotive and hyperthermic effects of (+)-3,4-methylenedioxymethamphetamine. Psychopharmacology (Berl). 2005 Apr;178(4):505-13.

Høverstad T, Midtvedt T. Short-chain fatty acids in germfree mice and rats. J Nutr. 1986 Sep; 116(9):1772-6.

Hylemon PB, Zhou H, Pandak WM, Ren S, Gil G, Dent P. Bile acids as regulatory molecules. J Lipid Res. 2009 Aug;50(8):1509-20. 
Ikegami R, Shimizu I, Sato T, Yoshida Y, Hayashi Y, Suda M, et al. Gamma-aminobutyric acid signaling in brown adipose tissue promotes systemic metabolic derangement in obesity. Cell Rep. 2018 Sep;24(11):2827-2837.e5.

Inagaki T, Moschetta A, Lee YK, Peng L, Zhao G, Downes $\mathrm{M}$, et al. Regulation of antibacterial defense in the small intestine by the nuclear bile acid receptor. Proc Natl Acad Sci USA. 2006 Mar;103(10):3920-5.

Inagaki $\mathrm{T}$, Tachibana $\mathrm{M}$, Magoori $\mathrm{K}$, Kudo $\mathrm{H}$, Tanaka T, Okamura M, et al. Obesity and metabolic syndrome in histone demethylase JHDM2a-deficient mice. Genes Cells. 2009 Aug;14(8):991-1001.

Ismail AS, Severson KM, Vaishnava S, Behrendt $\mathrm{CL}, \mathrm{Yu} \mathrm{X}$, Benjamin JL, et al. Gammadelta intraepithelial lymphocytes are essential mediators of host-microbial homeostasis at the intestinal mucosal surface. Proc Natl Acad Sci USA. 2011 May;108(21):8743-8.

Ivanov II, de Llanos Frutos R, Manel N, Yoshinaga K, Rifkin DB, Sartor RB, et al. Specific microbiota direct the differentiation of Th17 cells in the mucosa of the small intestine. Cell Host Microbe. 2008 Oct;4(4):337-49.

Jones BD, Mobley HL. Proteus mirabilis urease: genetic organization, regulation, and expression of structural genes. J Bacteriol. 1988 Aug; 170(8):3342-9.

Kasubuchi M, Hasegawa S, Hiramatsu T, Ichimura A, Kimura I. Dietary gut microbial metabolites, short-chain fatty acids, and host metabolic regulation. Nutrients. 2015 Apr;7(4): 2839-49.

Kelly CR, Khoruts A, Staley C, Sadowsky MJ, Abd $\mathrm{M}$, Alani M, et al. Effect of fecal microbiota transplantation on recurrence in multiply recurrent Clostridium difficile infection: a randomized trial. Ann Intern Med. 2016 Nov; 165(9):609-16.

Kendrick WC, Hull AR, Knochel JP. Rhabdomyolysis and shock after intravenous amphetamine administration. Ann Intern Med. 1977 Apr;86(4):381-7.

Kim D, Jitrapakdee S, Thompson M. Differential regulation of the promoter activity of the mouse UCP 2 and UCP 3 genes by MyoD and myogenin. J Biochem Mol Biol. 2007 Nov; 40(6):921-7.

Kim MH, Kang SG, Park JH, Yanagisawa M, Kim $\mathrm{CH}$. Short-chain fatty acids activate GPR41 and GPR43 on intestinal epithelial cells to promote inflammatory responses in mice. Gastroenterology. 2013 Aug;145(2):396-406.

Kimura I, Miyamoto J, Ohue-Kitano R, Watanabe $\mathrm{K}$, Yamada T, Onuki M, et al. Maternal gut microbiota in pregnancy influences offspring metabolic phenotype in mice. Science. 2020; 367(6481):eaaw8429.

Kiraly DD, Walker DM, Calipari ES, Labonte B, Issler $\mathrm{O}$, Pena $\mathrm{CJ}$, et al. Alterations of the host microbiome affect behavioral responses to cocaine. Sci Rep. 2016 Oct;6(1):35455.
Kiskinis E, Hallberg M, Christian M, Olofsson M, Dilworth SM, White R, et al. RIP140 directs histone and DNA methylation to silence Ucp1 expression in white adipocytes. EMBO J. 2007 Nov;26(23):4831-40.

Kitahara M, Takamine F, Imamura T, Benno Y. Clostridium hiranonis sp. nov., a human intestinal bacterium with bile acid 7alpha-dehydroxylating activity. Int J Syst Evol Microbiol. 2001 Jan;51(Pt 1):39-44.

Kiyatkin EA, Kim AH, Wakabayashi KT, Baumann MH, Shaham Y. Critical role of peripheral vasoconstriction in fatal brain hyperthermia induced by MDMA (Ecstasy) under conditions that mimic human drug use. J Neurosci. 2014 Jun;34(23):7754-62.

Kiyatkin EA, Kim AH, Wakabayashi KT, Baumann $\mathrm{MH}$, Shaham Y. Effects of social interaction and warm ambient temperature on brain hyperthermia induced by the designer drugs methylone and MDPV. Neuropsychopharmacology. 2015 Jan;40(2):436-45.

Kozak UC, Kopecky J, Teisinger J, Enerbäck S, Boyer B, Kozak LP. An upstream enhancer regulating brown-fat-specific expression of the mitochondrial uncoupling protein gene. Mol Cell Biol. 1994 Jan;14(1):59-67.

Krautkramer KA, Kreznar JH, Romano KA, Vivas EI, Barrett-Wilt GA, Rabaglia ME, et al. Dietmicrobiota interactions mediate global epigenetic programming in multiple host tissues. Mol Cell. 2016 Dec;64(5):982-92.

Labbé A, Ganopolsky JG, Martoni CJ, Prakash S, Jones ML. Bacterial bile metabolising gene abundance in Crohn's, ulcerative colitis and type 2 diabetes metagenomes. PLoS One. 2014 Dec;9(12):e115175.

Lach G, Schellekens H, Dinan TG, Cryan JF. Anxiety, Depression, and the microbiome: a role for gut peptides. Neurotherapeutics. 2018 Jan; 15(1):36-59.

Lanni A, Beneduce L, Lombardi A, Moreno M, Boss O, Muzzin P, et al. Expression of uncoupling protein-3 and mitochondrial activity in the transition from hypothyroid to hyperthyroid state in rat skeletal muscle. FEBS Lett. 1999 Feb;444(2-3):250-4.

Le Poul E, Loison C, Struyf S, Springael JY, Lannoy V, Decobecq ME, et al. Functional characterization of human receptors for short chain fatty acids and their role in polymorphonuclear cell activation. J Biol Chem. 2003 Jul;278(28):25481-9.

Lee MR. The history of Ephedra (ma-huang). J R Coll Physicians Edinb. 2011 Mar;41(1):7884.

Leonardsson G, Steel JH, Christian M, Pocock V, Milligan S, Bell J, et al. Nuclear receptor corepressor RIP140 regulates fat accumulation. Proc Natl Acad Sci USA. 2004 Jun;101(22): 8437-42.

Li B, Li L, Li M, Lam SM, Wang G, Wu Y, et al. Microbiota depletion impairs thermogenesis of brown adipose tissue and browning of white adipose tissue. Cell Rep. 2019 Mar; 26(10):2720-2737.e5.
Li X, Eisenach JC. Nicotinic acetylcholine receptor regulation of spinal norepinephrine release. Anesthesiology. 2002 Jun;96(6):1450-6.

Lin HV, Frassetto A, Kowalik EJ Jr, Nawrocki AR, Lu MM, Kosinski JR, et al. Butyrate and propionate protect against diet-induced obesity and regulate gut hormones via free fatty acid receptor 3-independent mechanisms. PLoS One. 2012;7(4):e35240.

Liu J, Jing X, Gan L, Sun C. The JAK2/STAT3 signal pathway regulates the expression of genes related to skeletal muscle development and energy metabolism in mice and mouse skeletal muscle cells. Biosci Biotechnol Biochem. 2012;76(10):1866-70.

Lockie SH, Heppner KM, Chaudhary N, Chabenne JR, Morgan DA, Veyrat-Durebex C, et al. Direct control of brown adipose tissue thermogenesis by central nervous system glucagon-like peptide-1 receptor signaling. Diabetes. 2012 Nov;61(11):2753-62.

Lowe PP, Gyongyosi B, Satishchandran A, Iracheta-Vellve A, Cho Y, Ambade A, et al. Reduced gut microbiome protects from alcoholinduced neuroinflammation and alters intestinal and brain inflammasome expression. Neuroinflammation. 2018 Oct;15(1):298.

Macfarlane S, Macfarlane GT. Regulation of short-chain fatty acid production. Proc Nutr Soc. 2003 Feb;62(1):67-72.

Manichanh C, Reeder J, Gibert P, Varela E, Llopis $\mathrm{M}$, Antolin M, et al. Reshaping the gut microbiome with bacterial transplantation and antibiotic intake. Genome Res. 2010 Oct;20(10): 1411-9.

Marin TL, Gongol B, Zhang F, Martin M, Johnson $\mathrm{DA}$, Xiao $\mathrm{H}$, et al. AMPK promotes mitochondrial biogenesis and function by phosphorylating the epigenetic factors DNMT1, RBBP7, and HAT1. Sci Signal. 2017 Jan; 10(464):eaaf7478. https://doi.org/10.1126/ scisignal.aaf 7478

Martin CR, Osadchiy V, Kalani A, Mayer EA. The brain-gut-microbiome axis. Cell Mol Gastroenterol Hepatol. 2018 Apr;6(2):133-48.

Maruyama T, Tanaka K, Suzuki J, Miyoshi H, Harada N, Nakamura T, et al. Targeted disruption of $\mathrm{G}$ protein-coupled bile acid receptor 1 (Gpbar1/M-Bar) in mice. J Endocrinol. 2006 Oct;191(1):197-205.

Maslowski KM, Vieira AT, Ng A, Kranich J, Sierro F, Yu D, et al. Regulation of inflammatory responses by gut microbiota and chemoattractant receptor GPR43. Nature. 2009 Oct;461(7268):1282-6.

Mechan AO, Esteban B, O’Shea E, Elliott JM, Colado MI, Green AR. The pharmacology of the acute hyperthermic response that follows administration of 3,4-methylenedioxymethamphetamine (MDMA, 'ecstasy') to rats. Br J Pharmacol. 2002 Jan;135(1):170-80.

Mills EM, Banks ML, Sprague JE, Finkel T. Pharmacology: uncoupling the agony from ecstasy. Nature. 2003 Nov;426(6965):403-4.
The Microbiome and Drug-Induced Hyperthermia
Brain Behav Evol 2020;95:256-271 DOI: $10.1159 / 000512098$ 
Mittal R, Debs LH, Patel AP, Nguyen D, Patel K, O'Connor G, et al. Neurotransmitters: the critical modulators regulating gut-brain axis. J Cell Physiol. 2017 Sep;232(9):2359-72.

Nagai S, Ikeda K, Horie-Inoue K, Shiba S, Nagasawa S, Takeda S, et al. Estrogen modulates exercise endurance along with mitochondrial uncoupling protein 3 downregulation in skeletal muscle of female mice. Biochem Biophys Res Commun. 2016 Nov;480(4):758-64.

Nash JF. Ketanserin pretreatment attenuates MDMA-induced dopamine release in the striatum as measured by in vivo microdialysis. Life Sci. 1990;47(26):2401-8.

National Forensic Laboratory Information System. [Internet] DRUG snapshot [cited Dec 2019]. Available from: https://www.nflis. deadiversion.usdoj.gov/DesktopModules/ ReportDownloads/Reports/NFLIS_Snapshot_122019.pdf

Noureldein MH, Bitar S, Youssef N, Azar S, Eid AA. Butyrate modulates diabetes-linked gut dysbiosis: epigenetic and mechanistic modifications. J Mol Endocrinol. 2020 Jan;64(1):2942.

O'Connor AD, Padilla-Jones A, Gerkin RD, Levine M. Prevalence of rhabdomyolysis in sympathomimetic toxicity: a comparison of stimulants. J Med Toxicol. 2015 Jun;11(2): 195-200.

Özoğul F, Kuley E, Özoğul Y, Özoğul İ. The function of lactic acid bacteria on biogenic amines production by food-borne pathogens in arginine decarboxylase broth. Food Sci Technol Res. 2012;18(6):795-804.

Patterson E, Cryan JF, Fitzgerald GF, Ross RP, Dinan TG, Stanton C. Gut microbiota, the pharmabiotics they produce and host health. Proc Nutr Soc. 2014 Nov;73(4):477-89.

Pedersen NP, Blessing WW. Cutaneous vasoconstriction contributes to hyperthermia induced by 3,4-methylenedioxymethamphetamine (ecstasy) in conscious rabbits. J Neurosci. 2001 Nov;21(21):8648-54.

Rabelo R, Schifman A, Rubio A, Sheng X, Silva JE. Delineation of thyroid hormone-responsive sequences within a critical enhancer in the rat uncoupling protein gene. Endocrinology. 1995 Mar; 136(3):1003-13.

Reigstad CS, Salmonson CE, Rainey JF 3rd, Szurszewski JH, Linden DR, Sonnenburg JL, et al. Gut microbes promote colonic serotonin production through an effect of short-chain fatty acids on enterochromaffin cells. FASEB J. 2015 Apr;29(4):1395-403.

Remely M, Aumueller E, Merold C, Dworzak S, Hippe B, Zanner J, et al. Effects of short chain fatty acid producing bacteria on epigenetic regulation of FFAR3 in type 2 diabetes and obesity. Gene. 2014 Mar;537(1):85-92.

Ridge EA, Pachhain S, Choudhury SR, Bodnar SR, Larsen RA, Phuntumart V, et al. The influence of the host microbiome on 3,4-methylenedioxymethamphetamine (MDMA)-induced hyperthermia and vice versa. Sci Rep. 2019 Mar;9(1):4313-3.
Ridlon JM, Harris SC, Bhowmik S, Kang DJ, Hylemon PB. Consequences of bile salt biotransformations by intestinal bacteria. Gut Microbes. 2016;7(1):22-39.

Ridlon JM, Kang DJ, Hylemon PB, Bajaj JS. Bile acids and the gut microbiome. Curr Opin Gastroenterol. 2014 May;30(3):332-8.

Ridlon JM, Kang DJ, Hylemon PB. Bile salt biotransformations by human intestinal bacteria. J Lipid Res. 2006 Feb;47(2):241-59.

Riley CL, Dao C, Kenaston MA, Muto L, Kohno S, Nowinski SM, et al. The complementary and divergent roles of uncoupling proteins 1 and 3 in thermoregulation. J Physiol. 2016 Dec;594(24):7455-64.

Robidoux J, Cao W, Quan H, Daniel KW, Moukdar F, Bai X, et al. Selective activation of mitogen-activated protein (MAP) kinase kinase 3 and p38a MAP kinase is essential for cyclic AMP-dependent UCP1 expression in adipocytes. Mol Cell Biol. 2005 Jul;25(13):5466-79.

Rosenbaum M, Knight R, Leibel RL. The gut microbiota in human energy homeostasis and obesity. Trends Endocrinol Metab. 2015 Sep; 26(9):493-501.

Rusyniak DE, Sprague JE. Toxin-induced hyperthermic syndromes. Med Clin North Am. 2005 Nov;89(6):1277-96.

Sampson TR, Debelius JW, Thron T, Janssen S, Shastri GG, Ilhan ZE, et al. Gut microbiota regulate motor deficits and neuroinflammation in a model of Parkinson's disease. Cell. 2016 Dec;167(6):1469-1480.e12.

Sánchez C. The effects of dopamine D-1 and D-2 receptor agonists on body temperature in male mice. Eur J Pharmacol. 1989 Nov;171(23):201-6.

Sanchez-Alavez M, Conti B, Wood MR, Bortell N, Bustamante E, Saez E, et al. ROS and sympathetically mediated mitochondria activation in brown adipose tissue contribute to methamphetamine-induced hyperthermia. Front Endocrinol (Lausanne). 2013 Apr;4:44.

Sayin SI, Wahlström A, Felin J, Jäntti S, Marschall HU, Bamberg K, et al. Gut microbiota regulates bile acid metabolism by reducing the levels of tauro-beta-muricholic acid, a naturally occurring FXR antagonist. Cell Metab. 2013 Feb;17(2):225-35.

Screaton GR, Singer M, Cairns HS, Thrasher A, Sarner M, Cohen SL. Hyperpyrexia and rhabdomyolysis after MDMA ("ecstasy") abuse. Lancet. 1992 Mar;339(8794):677-8.

Sears IB, MacGinnitie MA, Kovacs LG, Graves RA. Differentiation-dependent expression of the brown adipocyte uncoupling protein gene: regulation by peroxisome proliferatoractivated receptor gamma. Mol Cell Biol. $1996 \mathrm{Jul} ; 16(7): 3410-9$.

Selwyn FP, Csanaky IL, Zhang Y, Klaassen CD. Importance of large intestine in regulating bile acids and glucagon-like peptide- 1 in germ-free mice. Drug Metab Dispos. 2015 Oct;43(10):1544-56.
Sharma HS, Johanson CE. Intracerebroventricularly administered neurotrophins attenuate blood cerebrospinal fluid barrier breakdown and brain pathology following whole-body hyperthermia: an experimental study in the rat using biochemical and morphological approaches. Ann N Y Acad Sci. 2007 Dec; 1122(1):112-29.

Sochocka M, Donskow-Łysoniewska K, Diniz BS, Kurpas D, Brzozowska E, Leszek J. The gut microbiome alterations and inflammationdriven pathogenesis of Alzheimer's disease-a critical review. Mol Neurobiol. 2019 Mar; 56(3):1841-51.

Solanes G, Pedraza N, Calvo V, Vidal-Puig A, Lowell BB, Villarroya F. Thyroid hormones directly activate the expression of the human and mouse uncoupling protein-3 genes through a thyroid response element in the proximal promoter region. Biochem J. 2005 Mar;386(Pt 3):505-13.

Solanes G, Pedraza N, Iglesias R, Giralt M, Villarroya $F$. Functional relationship between MyoD and peroxisome proliferator-activated receptor-dependent regulatory pathways in the control of the human uncoupling protein-3 gene transcription. Mol Endocrinol. 2003 Oct;17(10): 1944-58.

Sprague JE, Banks ML, Cook VJ, Mills EM. Hypothalamic-pituitary-thyroid axis and sympathetic nervous system involvement in hyperthermia induced by 3,4-methylenedioxymethamphetamine (Ecstasy). J Pharmacol Exp Ther. 2003 Apr;305(1):159-66.

Sprague JE, Riley CL, Mills EM. Body temperature regulation and drugs of abuse. In: Romanovsky AA, editor. Thermoregulation, Part II. San Diego (CA): Elsevier BV; 2018. pp. 623-34.

Sprague JE, Yang X, Sommers J, Gilman TL, Mills EM. Roles of norepinephrine, free Fatty acids, thyroid status, and skeletal muscle uncoupling protein 3 expression in sympathomimetic-induced thermogenesis. J Pharmacol Exp Ther. 2007 Jan;320(1):274-80.

Strandwitz P. Neurotransmitter modulation by the gut microbiota. Brain Res. 2018;1693(Pt B): $128-33$

Sudo N, Chida Y, Aiba Y, Sonoda J, Oyama N, Yu $\mathrm{XN}$, et al. Postnatal microbial colonization programs the hypothalamic-pituitary-adrenal system for stress response in mice. J Physiol. 2004 Jul;558(Pt 1):263-75.

Sudo N. Biogenic amines: signals between commensal microbiota and gut physiology. Front Endocrinol (Lausanne). 2019 Jul; 10:504.

Sundaresan M, Yu ZX, Ferrans VJ, Irani K, Finkel T. Requirement for generation of $\mathrm{H} 2 \mathrm{O} 2$ for platelet-derived growth factor signal transduction. Science. 1995 Oct;270(5234):296-9.

Takahashi K, Sugi Y, Nakano K, Tsuda M, Kurihara $\mathrm{K}$, Hosono A, et al. Epigenetic control of the host gene by commensal bacteria in large intestinal epithelial cells. J Biol Chem. 2011 Oct;286(41):35755-62. 
Tanida M, Shen J, Maeda K, Horii Y, Yamano T, Fukushima Y, et al. High-fat diet-induced obesity is attenuated by probiotic strain Lactobacillus paracasei ST11 (NCC2461) in rats. Obes Res Clin Pract. 2008 Sep;2(3):I-II.

Tansey EA, Johnson CD. Recent advances in thermoregulation. Adv Physiol Educ. 2015 Sep; 39(3):139-48

Tateishi K, Okada Y, Kallin EM, Zhang Y. Role of Jhdm2a in regulating metabolic gene expression and obesity resistance. Nature. $2009 \mathrm{Apr}$; 458(7239):757-61.

Thomas C, Gioiello A, Noriega L, Strehle A, Oury J, Rizzo G, et al. TGR5-mediated bile acid sensing controls glucose homeostasis. Cell Metab. 2009 Sep;10(3):167-77.

Tsavkelova EA, Botvinko IV, Kudrin VS, Oleskin $A V$. Detection of neurotransmitter amines in microorganisms with the use of high-performance liquid chromatography. Dokl Biochem. 2000 May-Jun;372(1-6):115-7.

Tsuchida A, Nonomura T, Ono-Kishino M, Nakagawa T, Taiji M, Noguchi $\mathrm{H}$. Acute effects of brain-derived neurotrophic factor on energy expenditure in obese diabetic mice. Int J Obes Relat Metab Disord. 2001 Sep;25(9):1286-93.
Vidal-Puig A, Solanes G, Grujic D, Flier JS, Lowell BB. UCP3: an uncoupling protein homologue expressed preferentially and abundantly in skeletal muscle and brown adipose tissue. Biochem Biophys Res Commun. 1997 Jun; 235(1):79-82.

Villarroya F, Iglesias R, Giralt M. PPARs in the control of uncoupling proteins gene expression. PPAR Res. 2007;2007:74364.

Wallinga AE, Grahlmann C, Granneman RA, Koolhaas JM, Buwalda B. Gender differences in hyperthermia and regional 5-HT and 5-HIAA depletion in the brain following MDMA administration in rats. Brain Res. 2011 Jun;1398:13-20.

Wang C, Bomberg E, Billington CJ, Levine AS, Kotz CM. Brain-derived neurotrophic factor (BDNF) in the hypothalamic ventromedial nucleus increases energy expenditure. Brain Res. 2010 Jun;1336:66-77.

Watanabe M, Houten SM, Mataki C, Christoffolete MA, Kim BW, Sato H, et al. Bile acids induce energy expenditure by promoting intracellular thyroid hormone activation. Nature. 2006 Jan;439(7075):484-9.

Wei M, Huang F, Zhao L, Zhang Y, Yang W, Wang S, et al. A dysregulated bile acid-gut microbiota axis contributes to obesity susceptibility. EBioMedicine. 2020 May;55:102766.
Winston JA, Theriot CM. Diversification of host bile acids by members of the gut microbiota. Gut Microbes. 2020;11(2):158-71.

Wostmann BS. Intestinal bile acids and cholesterol absorption in the germfree rat. J Nutr. 1973 Jul;103(7):982-90.

Wyeth RP, Mills EM, Ullman A, Kenaston MA, Burwell J, Sprague JE. The hyperthermia mediated by 3,4-methylenedioxymethamphetamine (MDMA, Ecstasy) is sensitive to sex differences. Toxicol Appl Pharmacol. 2009 Feb;235(1):33-8.

Yubero P, Barberá MJ, Alvarez R, Viñas O, Mampel T, Iglesias R, et al. Dominant negative regulation by c-Jun of transcription of the uncoupling protein-1 gene through a proximal cAMP-regulatory element: a mechanism for repressing basal and norepinephrine-induced expression of the gene before brown adipocyte differentiation. Mol Endocrinol. 1998 Jul;12(7):1023-37.

Zhou W, Sailani MR, Contrepois K, Zhou Y, Ahadi S, Leopold SR, et al. Longitudinal multiomics of host-microbe dynamics in prediabetes. Nature. 2019 May;569(7758):663-71. 